\title{
Sexual harassment and victimization of students: a case study of a higher education institution in South Africa
}

\author{
Helen Oni $T^{1}$, Takalani Tshitangano $G^{2}$, Henry Akinsola $A^{3}$
}

1. Department of Public Health, University of Venda, Thohoyandou, 0950, South Africa. Postal address: University of Venda, Private Bag X5050. Thohoyandou. 0950. Phone Number: $(+27) 718389850$.

Email: greattosin17@gmail.com

2. Department of Public Health, University of Venda, Thohoyandou, 0950, South Africa. Email: Takalani. Phone Number: (+27) 824484111. Tshitangano@univen.ac.za

3.Department of Public Health, University of Venda, Thohoyandou, 0950, South Africa. Phone Number: (+27) 781113792. Email: henry.akinsola@univen.ac.za

\begin{abstract}
Introduction: Sexual harassment has been identified as a major public health problem that is hidden in most institutions/organizations.

Objective: This study assessed sexual harassment and victimization of students in a higher institution in South Africa.

Methods: A quantitative, cross-sectional descriptive design was used in this study. The target population was registered students of the higher education institution and the sample size was 342. Questionnaire was used for data collection and data were analyzed using Statistical Package for Social Sciences (SPSS) Version 23.0 program. The basic principles of ethics were duly observed and the ethical clearance certificate was obtained prior to data collection.

Results: The findings revealed that $27(17.3 \%)$ of the male and $47(25.5 \%)$ of the female respondents $(\mathrm{P}=0.047)$ had personally experienced unwanted touching. Two $(1.3 \%)$ male and $5(2.7 \%)$ female students admitted that they have been raped. Seventeen $(10.8 \%)$ of the males and $19(10.2 \%)$ of the females had been coerced to comply with a sexual relationship on campus.

Conclusion: This study shows that both male and female students on campus are experiencing different forms of sexual harassment.

Keywords: Students, sexual harassment, higher education institution.

DOI: https://dx.doi.org/10.4314/ahs.v19i1.21

Cite as: Oni HT, Tshitangano TG, Akinsola HA. Sexual harassment and victimization of students: a case study of a bigher education institution in South Africa. Afri Health Sci. 2019;19(1). 1478-1485. bttps:// dx.doi. org/10.4314/ abs. v19i1.21
\end{abstract}

\section{Introduction}

Sexual harassment refers to as persistent, unsolicited and unwelcomed sexual advances which could be visual, physical, verbal and non-verbal gestures and it is seen

\section{Corresponding author: \\ Helen Oni T, \\ Department of Public Health, University of Venda, \\ Thohoyandou, 0950, South Africa \\ Postal address: University of Venda, \\ Private Bag X5050. Thohoyandou. 0950. \\ Phone Number: (+27)718389850 \\ Email: greattosin17@gmail.com}

as a disease of present-day learning institutions ${ }^{1}$. It has been identified as one of the major stressors that constitute a threat to the performance of an individual in organisations or academic institutions ${ }^{2}$. According to Dziech and Weiner ${ }^{3}$, Catharine MacKinnon viewed sexual harassment of learners, particularly female learners as a form of women abuse and invented the term 'sexual harassment'. The Code of Good Practice on the Handling of Sexual Harassment Cases had made South Africa one of the countries around the globe which had specifically designed legislation to deal with sexual harassment. The Code (1998) defined sexual harassment as "unwanted conduct of a sexual nature". The "unwanted and potentially coercive or disruptive nature" distinguished sexual

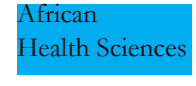

(C) 2019 Oni et al. Licensee African Health Sciences. This is an Open Access article distributed under the terms of the Creative commons Attribution License (https://creativecommons.org/licenses/BY/4.0), which permits unrestricted use, distribution, and reproduction in any medium, provided the original work is properly cited. 
harassment from consensual behaviour that is welcomed and mutual ${ }^{4,5,6}$. Parrot and Bechhofer ${ }^{7}$ identified factors that put both students and staffs at risk of being sexually harassed in school settings. These include university community social structure, alcohol and substance abuse, absence and ineffective implementation of policy on sexual harassment and failure of victims to report the incidence.

Sexual harassment perpetrator could be a colleague, supervisor, management personnel and/or student. The perpetrator and victim may be of the same gender ${ }^{8}$. However, in most incidents, men had been found to be perpetrators either in the learning institutions or work plac$\mathrm{es}^{9}$. It has been documented that most victims of sexual harassment show cognitive, behavioural, emotional, and physical symptoms following harassment that may persist long after the harassment has ended and even change the course of their lifestyles ${ }^{10-13}$. Families, communities and society at large are not excluded from the adverse consequences of sexual harassment ${ }^{10,13}$.

In developed countries, studies had been conducted to determine the prevalence of sexual harassment at the various higher education institutions as well as its impact on the victims. In the United States of America, studies showed that sexual harassment in higher education institutions takes place more frequently than people imagined $^{13}$. A study at Brown University in the United States revealed that among 234 female students, there was an incidence of $6 \%$ attempted rape and $3.8 \%$ rape cases ${ }^{14}$. In another study conducted by So-Kum Tang, Critelli, and Porter ${ }^{15}$ at the Chinese University of Hong Kong in China among undergraduate female students; of the total participants, there was $14.9 \%$ reported cases of attempted rape and $1.4 \%$ of rape cases.

In Africa, few studies had also shown a high incidence of sexual harassment. For an instant a study conducted at the University of Malawi showed $67 \%$ of sexual harassment on campus and $12.6 \%$ of the students were raped ${ }^{16}$. Similarly, in South Africa studies showed that $30 \%$ of female leaners were raped and sexually harassed by male learners and teachers in high schools ${ }^{17}$. Meanwhile, the extent of this problem is unknown in higher education institutions and study of this kind is rare in South Afri$\mathrm{ca}^{17}$. It is important to determine the prevalence of sexual harassment in every institution so as to develop strategies that will help in prevention and reduction of its occur- rence. Therefore, this study aimed to determine sexual harassment occurrence and victimization of students in one of the biggest higher education institutions in South Africa.

\section{Methods section Study design}

The study adopted a quantitative cross-sectional descriptive survey design ${ }^{18}$.

\section{Study setting}

The study was conducted in one of the higher education institutions in Limpopo province of South Africa. The higher education institution has a total number of 13693 enrolled students for the 2014 academic year which spread across various schools. These schools offer qualifications such as certificates, undergraduate degrees as well as post-graduate qualifications. The student population is diverse with students from Africa countries such as Nigeria, Zimbabwe, and Swaziland.

\section{Population and sample}

The target population of this study was students who are 18 years and above, residing on campus. There was a total number of 2165 bed spaces with 1176 (54.32\%) allocated to female students and $989(45.68 \%)$ allocated to male students on campus. The sample size 338 was calculated using the Slovin's formula, $[\mathrm{n}=\mathrm{N} /\{1+\mathrm{Ne} 2\}]$, where "N" is the total number of resident students, " $n$ " is the sample size and " $e$ " is the accepted level of error which is 0.05 . Systematic sampling was used to select students' room numbers. This is calculated by dividing the total number of the rooms by the sample size to find " $k$ " value which is the interval value $\left(2165 / 338=6^{\text {th }}\right)$. Therefore, every room was selected for the study. The first room, to begin with, was chosen using simple random sampling ${ }^{19}$.

Validity and reliability of the data collection instrument Questionnaire was used to collect data from participants. The questionnaire was developed based on extensive literature review, coupled with expert consultation in assessing the representativeness of the questions on the variables under study to ensure validity. In addition, the questionnaire was structured in simple English to avoid ambiguity and the participants were allowed to go through it while the researcher was still around so as to clarify any concerns. 
The reliability of the questionnaire was measured using the test-retest method. The questionnaire was administered to a small sample of 38 students who did not participate in the main study twice at an interval of one week. The Cronbach Alpha correlation was calculated and a correlation coefficient of 0.87 was established, which fell within the acceptable limit ${ }^{19}$.

\section{Data collection procedure}

A self-administered questionnaire was used for data collection. Data collection began on the $2^{\text {nd }}$ of April, 2015 and lasted for 30 days. In order to achieve a high level of questionnaire return and study objectives, though the calculated sample size for this study was 338, a total of 400 questionnaires were administered. The questionnaire was administered in each participant's room. Three hundred and fifty questionnaires were collected out of 400 distributed, giving a return rate of $87.50 \%$. Eight questionnaires were not properly completed and were excluded from the study. In total 342 questionnaires were analysed. Due to the sensitive nature of this study, prior arrangement was made with the two of the institution's counsellors and each participant were provided with their contacts for counselling consultation.

\section{Informed consent and confidentiality}

The information sheet and consent form were given to each participant to sign. The researcher ensured that all the essential information such as the purpose of the study, the significance of the study, assurance of anonymity and confidentiality as well as voluntary participation were provided in the information sheet, so as to enable the participants to make an informed decision before signing the form. Only the individuals who tender their written informed consent were allowed to participate in the study. Confidentiality and anonymity were ensured by requesting the participants not to write their names or provide any form of identification on the questionnaire and consent form. Completed questionnaires were kept under lock and key and the information provided by the participants were only used for the purpose of this study.

\section{Data analysis}

Statistical Package for Social Science (SPSS) version 23.0 program was used for analysis of data. Chi-Square test is used to check the statistical significant difference between two variables. Statistical significance is set at $p<0.05$ and confidence interval at $95 \%$.

\section{Ethical procedure}

The basic principles of ethics were duly observed and the ethical clearance certificate to conduct this study was issued in February, 2015 by the University of Venda, Health, Safety and Research Ethics Committee: SHS/15/ $\mathrm{PH} / 05 / 1903$. Access to the participating students was granted by the appropriate authorities. Participants were instructed to read the information page which explained the purpose of the study, ensure anonymity and confidentiality as well as voluntary participation before signing the consent form attached to the first page of the questionnaire.

\section{Results}

\section{Demographic information of the respondents}

A total of 342 students consisting of $186(54.39 \%)$ males and $156(46.61 \%)$ females participated in the study. Participants' ages ranged from 18 to 40 years. As shown in Table 1 , the majority $(n=282 ; 82.46 \%)$ were in the $18-24$ age group. Most of the participants were at degree level. One hundred and eighty-five (54.09\%) and 131 (38.30\%) respectively had spent up to four years at the higher education institution. 
Table 1: Demographic distribution of the respondents ( $\mathrm{N}=342)$

\begin{tabular}{|c|c|c|c|c|c|c|}
\hline & \multicolumn{5}{|l|}{ Age } & \multirow{4}{*}{$\begin{array}{l}\text { Total } \\
\mathrm{n}(\%)\end{array}$} \\
\hline & $\geq 18-24 y r s$ & $25-29 y r s$ & $30-34 y r s$ & $35-39 \mathrm{yrs}$ & $\geq 40$ & \\
\hline & & & & & & \\
\hline & $\mathrm{n}(\%)$ & $\mathrm{n}(\%)$ & n $(\%)$ & $\mathrm{n}(\%)$ & $\mathrm{n}(\%)$ & \\
\hline \multicolumn{7}{|l|}{ Gender } \\
\hline Male & $132(35.48)$ & $23(6.73)$ & $1(0.29)$ & $0(0.00)$ & $0(0.0)$ & $156(45.6)$ \\
\hline Female & $150(43.86)$ & $22(6.43)$ & $4(1.17)$ & $3(0.88)$ & $7(2.1)$ & $186(54.4)$ \\
\hline Total & $282(82.46)$ & $45(13.16)$ & $5(1.46)$ & $3(0.88)$ & $7(2.1)$ & $342(100)$ \\
\hline \multicolumn{7}{|l|}{ Level of Education } \\
\hline Certificate level & $9(2.63)$ & $0(0.00)$ & $0(0.00)$ & $0(0.00)$ & $0(0.0)$ & $9(2.6)$ \\
\hline Diploma level & $1(0.29)$ & $1(0.29)$ & $0(0.00)$ & $0(0.00)$ & $0(0.0)$ & $2(0.5)$ \\
\hline Degree level & $259(75.73)$ & $32(9.36)$ & $5(1.46)$ & $2(0.54)$ & $7(2.1)$ & $305(89.2)$ \\
\hline Postgraduate level & $13(3.80)$ & $12(3.51)$ & $0(0.00)$ & $1(0.29)$ & $0(0.0)$ & $26(7.6)$ \\
\hline Total & $282(82.47)$ & $45(13.16)$ & $5(1.46)$ & $3(0.88)$ & $7(2.1)$ & $342(100)$ \\
\hline \multicolumn{7}{|c|}{ Year spent in the higher education institution } \\
\hline $1-2 \mathrm{yrs}$ & $168(49.12)$ & $10(2.92)$ & $2(0.58)$ & $2(0.6)$ & $3(0.9)$ & $185(54.1)$ \\
\hline $3-4 \mathrm{yrs}$ & $102(29.82)$ & $21(6.14)$ & $3(0.88)$ & $1(0.3)$ & $4(1.2)$ & $131(38.3)$ \\
\hline $5-6 \mathrm{yrs}$ & $11(3.21)$ & $10(2.92)$ & $0(0.0)$ & $0(0.0)$ & $0(0.0)$ & $21(6.1)$ \\
\hline
\end{tabular}

Whilst only 6(0.60\%) participants were married, an overwhelming majority $(n=334 ; 97.66 \%)$ indicated that they were single. The dominant $(n=339 ; 99.12 \%)$ faith among the participants was the Christian religion, and this was followed by $1(0.29 \%)$ participant who reported belonging to the Muslim religion.

\section{Occurrence of sexual harassment and victimization} of students in the higher education institution

Table 2 shows the percentage distribution of the respondents regarding occurrence of sexual harassment and students' victimization in the higher education institution by gender. In this section of the questionnaire, due to some missing data, the ' $n$ ' also varied slightly from one variable to the other. With regards to contact sexual harassment, amongst males, $17.3 \%$ experienced unwanted touching, $36.5 \%$ observed unwanted touching and $46.2 \%$ were aware of unwanted touching. Among females, $25.3 \%$ personally experienced unwanted touching, $35.5 \%$ observed unwanted touching and $39.2 \%$ were aware of unwanted touching. However, $1.3 \%$ males had personally experienced rape, $10.9 \%$ had observed it and $87.8 \%$ were aware of it. While $2.7 \%$ females admitted that they have been raped, $4.3 \%$ had observed it and $93.0 \%$ were just aware of such incident. 
The distribution according to the frequency of verbal harassment shows that $12.2 \%$ of the males and $18.4 \%$ of the females $(\mathrm{P}=0.017)$ had personally experienced unwanted sexual advance. Only $37.4 \%$ of the male and $39.2 \%$ of the female students had observed sex-related jokes on campus. The results with regards to non-verbal harassment, an equal percentage (16.7\%) of both male and female students had personally experienced unwanted sexual oriented text messages.
Regarding the variables under quid pro quo harassment, $10.8 \%$ of the male students had been coerced to comply with a sexual relationship, $18.6 \%$ had observed it and $70.5 \%$ were aware of it. Meanwhile, $10.2 \%$ of the female students had personally experienced coerced sexual relationship, $18.6 \%$ had observed it and $74.2 \%$ were aware of it. Of the study group, $8(5.1 \%)$ of the male and 10 $(5.4 \%)$ of the female respondents had been intimidated into submitting to unwanted sexual advances in return for marks. While, $117(75.0 \%)$ of the males and 142 (76.3\%) of the females were aware of such scenario.

Table 2: Percentage distribution of respondents regarding occurrence of sexual harassment and students' victimization in the institution by gender

\begin{tabular}{|c|c|c|c|c|c|c|c|c|c|}
\hline Variables & MALES & & & & FEM & & & & PValues \\
\hline $\begin{array}{l}\text { Occurrences of sexual harassment in } \\
\text { the University }\end{array}$ & $n$ & Personally experienced & Observed & Aware of & $n$ & Personally experienced & Observed & Aware of & (Chi-Square) \\
\hline $\begin{array}{l}\text { Physical Harassment } \\
\text { Unwanted touching }\end{array}$ & 156 & $17.3 \%$ & $36.5 \%$ & $46.2 \%$ & 186 & $25.3 \%$ & $35.5 \%$ & $39.2 \%$ & 0.177 \\
\hline Rape & 156 & $1.3 \%$ & $10.9 \%$ & $87.8 \%$ & 186 & $2.7 \%$ & $4.3 \%$ & $93.0 \%$ & 0.047 \\
\hline Attempted rape & 156 & $2.6 \%$ & $12.8 \%$ & $84.6 \%$ & 186 & $3.8 \%$ & $7.0 \%$ & $89.2 \%$ & 0.167 \\
\hline Unwanted hugging & 156 & $17.3 \%$ & $43.6 \%$ & $39.1 \%$ & 185 & $30.3 \%$ & $32.4 \%$ & $37.3 \%$ & 0.023 \\
\hline Unwanted kissing & 156 & $19.2 \%$ & $34.0 \%$ & $46.8 \%$ & 185 & $21.1 \%$ & $25.9 \%$ & $53.0 \%$ & 0.325 \\
\hline Unwanted fondling & 156 & $10.3 \%$ & $32.1 \%$ & $57.7 \%$ & 186 & $14.0 \%$ & $22.0 \%$ & $64.0 \%$ & 0.095 \\
\hline $\begin{array}{l}\text { Verbal harassment } \\
\text { Unwanted sexual advance }\end{array}$ & 156 & $12.2 \%$ & $28.8 \%$ & $59.0 \%$ & 186 & $18.4 \%$ & $16.8 \%$ & $64.9 \%$ & 0.017 \\
\hline Sex- related jokes & 156 & $31.4 \%$ & $35.3 \%$ & $33.3 \%$ & 186 & $33.3 \%$ & $30.6 \%$ & $36.0 \%$ & 0.662 \\
\hline Sex - related insults & 155 & $23.2 \%$ & $39.4 \%$ & $37.4 \%$ & 186 & $29.6 \%$ & $31.2 \%$ & $39.2 \%$ & 0.245 \\
\hline Comment about a person's body & 155 & $33.5 \%$ & $40.0 \%$ & $26.5 \%$ & 186 & $41.4 \%$ & $30.1 \%$ & $28.5 \%$ & 0.165 \\
\hline $\begin{array}{l}\text { Non-verbal harassment } \\
\text { Unwanted sexual gestures }\end{array}$ & 154 & $15.6 \%$ & $29.2 \%$ & $55.2 \%$ & 186 & $18.8 \%$ & $17.7 \%$ & $63.4 \%$ & 0.034 \\
\hline Unwanted sexually suggestive staring & 155 & $15.5 \%$ & $26.5 \%$ & $58.1 \%$ & 186 & $20.4 \%$ & $16.7 \%$ & 62.95 & 0.090 \\
\hline Unwanted sexually oriented letter & 155 & $9.7 \%$ & $18.7 \%$ & $71.6 \%$ & 185 & $6.5 \%$ & $17.3 \%$ & $76.2 \%$ & 0.486 \\
\hline Unwanted sexual oriented e-mail & 155 & $9.7 \%$ & $13.5 \%$ & $76.8 \%$ & 185 & $9.7 \%$ & $8.6 \%$ & $81.6 \%$ & 0.387 \\
\hline Unwanted sexual oriented text messages & 156 & $16.7 \%$ & $21.2 \%$ & $62.2 \%$ & 186 & $16.7 \%$ & $17.7 \%$ & $65.6 \%$ & 0.717 \\
\hline Unwanted sexual oriented phone calls & 155 & $21.9 \%$ & $24.5 \%$ & $53.5 \%$ & 186 & $18.3 \%$ & $12.4 \%$ & $69.4 \%$ & 0.007 \\
\hline $\begin{array}{l}\text { Quid Pro quo harassment } \\
\text { Coerced for sexual relations }\end{array}$ & 156 & $10.9 \%$ & $18.6 \%$ & $70.5 \%$ & 186 & $10.2 \%$ & $15.6 \%$ & $74.2 \%$ & 0.724 \\
\hline Treated better for sexual cooperation & 156 & $14.1 \%$ & $23.7 \%$ & $62.2 \%$ & 185 & $8.6 \%$ & $22.2 \%$ & $69.2 \%$ & 0.281 \\
\hline $\begin{array}{l}\text { Made to feel afraid for refusing to } \\
\text { cooperate to sexual relation }\end{array}$ & 156 & $7.7 \%$ & $23.7 \%$ & $68.6 \%$ & 186 & $11.3 \%$ & $22.6 \%$ & $66.1 \%$ & 0.532 \\
\hline $\begin{array}{l}\text { Treated bad for refusing to cooperate to } \\
\text { sexual relation }\end{array}$ & 155 & $9.7 \%$ & $25.2 \%$ & $65.2 \%$ & 186 & $11.3 \%$ & $22.6 \%$ & $66.1 \%$ & 0.647 \\
\hline $\begin{array}{l}\text { Intimidation of students into submitting } \\
\text { to unwanted sexual advances in return } \\
\text { for marks. }\end{array}$ & 156 & $5.1 \%$ & $19.9 \%$ & $75.0 \%$ & 186 & $5.4 \%$ & $18.3 \%$ & $76.3 \%$ & 0.931 \\
\hline
\end{tabular}




\section{Discussion}

The respondents in this study were youths mostly aged 18 to 24 years. The findings of this study indicate that both male and female students are experiencing sexual harassment on campus. A few of the respondents self-reported to have been raped, personally experienced attempted rape and unwanted kissing. Of note, there is a statistically significant difference between the variable of rape and gender $(\mathrm{P}=0.047)$, which shows that female students $(2.7 \%)$ are more likely to be raped. The aforementioned is similar to the findings of Norman et al. ${ }^{20}$ study on sexual harassment in public medical schools in Ghana. The authors reported that female students were two to three times more likely to be sexually harassed than their male counterparts. Not too dissimilar, a study in Uganda among higher education institution students revealed a higher rate of sexual harassment among female students $^{21}$.

Of note, this study focuses on both male and female students because it has been documented that any person irrespective of gender is prone to sexual harassment ${ }^{19,20}$. For instance, Luk-Fong et al. $^{22}$ reported that in Taiwan $50 \%$ of the female college students and one-sixth of male students had been sexually harassed.

Consistent with previous studies ${ }^{23-24}$, the results of this study revealed the common forms of sexual harassment experienced by the students. These include: unwanted touching, unwanted fondling, unwanted sexual advance, sex-related jokes, sex-related insults, unwanted sexual gestures and unwanted sexual oriented text messages, letters and phone calls, etc. Though, we expected a significant difference in all forms of sexual harassment between the female and the male students but to our surprise, sexual harassment among both genders are more or less the same, this is in line with a study conducted in Canada ${ }^{23}$. Though, the study took place in high schools but the findings were akin to the findings of this study. This is not unexpected since the settings are alike.

In educational setting quid pro quo sexual harassment is said to occur when a superior (supervisor/lecturer) conditions the granting of an economic/academic reward upon receipt of sexual favours from a subordinate/student or effuse fear by threatened the subordinate/student if he/she refuses to submit to his request ${ }^{25-27}$. Females mostly fall prey of this type of sexual harassment. Al- though, this study did not specify the harassers surprisingly the study revealed no significant difference between gender variables and quid pro quo form of sexual harassment. Therefore, we recommended a qualitative study to further explore this particular form of sexual harassment among higher education institutions students.

\section{Limitations of the study}

A limitation of this study is that the generalization of study findings to other South Africa's higher education institutions may not be possible since the study is a case study of a university. However, the results can still be vital in establishing a basis for comparison of the students' perceived occurrence of sexual harassment between various institutions. It can also serve as base-line data for future studies on the above subject.

\section{Conclusion and recommendations}

The findings revealed that both male and female students are experiencing sexual harassment in different forms. However, females are more likely to experience greater forms of sexual harassment such as rape. In order to prevent and mitigate sexual harassment in higher education institutions, the following are recommended:

- All sectors of the higher education institution should be made aware of the existence of the policy and how to use the grievance procedure, clearly spelling out the definition of sexual harassment. These efforts should especially be directed at the first-year female and male students when they arrive on campus. Clear guidelines pertaining to safety and facilities available on campus should be given to all students.

- A regular forum of stakeholders with management should take place at least once a semester, where cases and issues are discussed.

- The institution' management should make a clear statement about its seriousness of purpose in dealing with sexual harassment, and that such harassment will not be condoned under any circumstances.

- Regular communication about sexual harassment should take place through all the campuses media, such as the institution's radio station and notice boards.

- The sexual harassment policy should be reviewed to prescribe severe punishment for sexual harassment perpetrators and ensure confidentiality and anonymity in order to encourage the students to report cases of sexual harassment. 
- The Department of Human Resources in charge of the implementation of the policies should take responsibility for staffs and students training regarding sexual harassment and that a budget is allocated for this purpose, so as to promote effective implementation.

\section{Ethical approval}

Ethical clearance certificate (SHS/15/PH/05/1903), was issued by the University of Venda, Health, Safety and Research Ethics Committee to conduct the study.

\section{Informed consent}

A written informed consent was obtain from each participant after the purpose and participant rights had been clearly explained.

\section{Acknowledgement}

This study was funded by the National Research Funding, South Africa and University of Venda Research and Innovation Directorate. We acknowledge their support and kind gesture.

\section{Competing of Interest}

The authors declare that there is no financial or personal relationship(s) which may have inappropriately influenced the writing of this article.

\section{Acknowledgements}

The authors would like to appreciate the different authorities who gave permission to conduct this study. We also extend our appreciation to all the respondents in this study.

\section{Competing interest}

The authors declare that there is no financial or personal relationship(s) which may have inappropriately influenced the writing of this article.

\section{Funding declaration}

The study was funded by both the South Africa National Research Funding (NRF) and University of Venda.

\section{References}

1. Newman MA, Jackson RA. Sexual Harassment in the Federal Workplace Revisited: Influences On Sexual Harassment by Gender. Public Administration Review. 2004; 64(6): 705-717.
2. Ladebo O, Shopeju J. Sexual Harassment: Perceptions and Coping Strategies among Undergraduate Students in Nigeria. Acta Academica. 2004; 36(3):223-238.

3. Dziech BW, Weiner L. The Lecherous Professor: Sexual Harassment on Campus. 2nd ed. Chicago: University of Illinois Press Champaign. 1994.

4. Snyman-Van Deventer E, De Bruin J. Sexual harassment in South African and American law. Acta Academia Supplement. 2002; 1: 196-221.

5. De Wet A. Sexual Harassment of Learners in Secondary Schools: An Education Law Perspective. Thesis submitted in fulfillment of the requirements for the degree Philosophy Doctor in Education Law at the Potchefstroom Campus of the North-West University. Potchefstroom: North-West University. 2010.

6. Benson D, Thompson G. Sexual Harassment on a University Campus: The Confluence of Authority Relations, Sexual Interest and Gender Stratification. Social Problems. 1982; 29(3):236 - 251

7. Parrot A, Bechhofer L. Acquaintance Rape: The Hidden Crime. New York: Jobn Wiley \& Sons. 1991.

8. International Trade Union Confederation. Stop Sexual Harassment at Work- a Trade Union Guide. 2010. Retrieved February 03, 2014 from http://www.ituc-csi.org/ IMG/pdf/Harcelement_ENG_12pgs_BR.pdf.

9. Fitzgerald L, Weitzman L. Men who Harass: Speculation and Data. In Paludi, M. A. (Ed.). Sexual Harassment on Campus pp 125 - 140. New York: State University of New York Press. 1990.

10. Christofides C, Webster N, Jewkes R, Penn-Kekana L, Martin LJ, Abrahams N, Kim J. The state of sexual assault services: findings from a situation analysis of services in South Africa. The South African Gender-based Violence and Health Initiative report. 2003. Retrieved June 10, 2014, from http://www.mrc.ac.za/gender/sexualassault.pdf.

11. Martin LJ. Violence against Women: An Analysis of the Epidemiology and Patterns of Injury in Rape Homicide in Cape Town and in Rape in Johannesburg. A thesis submitted for MMed Forensic Pathology at University of Cape Town. Cape Town: University of Cape Town. 1999. 12. Jewkes R, Sen P, Garcia-Moreno C. In Krug E, Dahlberg LL, Mercy JA, Zwi AB, Lozano R (eds.). World Report On Violence and Health Geneva: World Health Organization Report. 2002; 213-239.

13. Steenkamp FR. The prevalence of sexual harassment within a student sample of Stellenbosch University. The- 
sis presented in partial fulfillment of the requirements for the Degree of Master of Arts (Psychology) at Stellenbosch University. Cape Town: Stellenbosch University. 2010.

14. Nasta A, Shah B, Brahmanandam S, Richman K, Wittels K, Allsworth J, Boardman L. Sexual Victimization: Incidence, Knowledge, and Resource use Among a Population of College Women. I Paediatr Adolesc Gynaecol. 2005; 18 (2): 91-96.

15. So-Kum Tang C, Critelli JW, Porter JF. Sexual aggression and victimization in dating relationships among Chinese College Students. Arch Sex Behav. 1995; 24(1): 47-53. 16. Ogbonnaya LU, Ogbonnaya CE, Emma-Echiegu NB. Prevalence of sexual harassment/victimization of female students in Ebonyi State University Abakaliki, southeast Nigeria. Journal of Community Medicine and Primary Health Care. 2011; 23 (1\&2): 56-57.

17. Smit D, Du Plessis V. Sexual Harassment in the Education Sector. Potchefstroom Electronic Law Journal. 2011; 6 (14): 173-217

18. Polit DF, Beck CT. Nursing research: principles and methods. 7th Ed. Philadelphia: Lippincott. 2008.

19. Creswell JW. Research design: Qualitative, Quantitative, and Mixed Methods Approaches $18^{\text {th }}$ Ed. Los Angeles: Sage. 2009.

20. Norman ID, Aikins M, Binka FN. Sexual Harassment in Public Medical Schools in Ghana. Ghana Med J. 2014; 47(3): 128-136.
21. Agardh A, Odberg-Pettersson K, Ostergren PO. Experience of Sexual Coercion and Risky Sexual Behaviour among Ugandan University Students. BMC Public Health. 2011; 10: 1471-2458.

22. Luk-Fong YP, Lee YA, Wong KD, Chong YS, LeeMan Y, Yeon YA, Yuen WG, Yuen W'T. Study on Students' Sexual Attitudes and Views on Sexual Harassment. Department of Special Education and Counselling. Hong Kong: The Hong Kong Institute of Education. 2013.

23. Chiodo D, Wolfe DA, Crooks C, Hughes R, Jaffe P. Impact of sexual harassment victimization by peers on subsequent adolescent victimization and adjustment: a longitudinal study. I Adolesc Health. 2009; 45: 46-52.

24. Dastile NP. Victimisation of Female students at theUniversity of Venda with Specific Reference to Sexual Harassment and Rape. A Thesis submitted in Partial Fulfilment of the Requirements for the Degree of Master of Arts at the Faculty of Humanities in the University of Pretoria. Pretoria: University of Pretoria. 2004.

25. Prinsloo S. Sexual Harassment and Violence in South African Schools. South African Journal of Education. 2006; 26(2): 305-318.

26. Human Rights Watch. Scared At School: Sexual Violence against Girls in South African Schools. New York: Human Rights Watch. 2001.

27. Dhlomo T, Mugweni RM, Shoniwa G, Maunganidze L, Sodi T. Perceived Sexual Harassment Among Female Students at a Zimbabwean Institution of Higher Learning. J Psychol Afr. 2012; 22(2): 269-272. 